\title{
Adherence to treatment: Doctor vs patient perspective
}

\author{
Farrukh Shah, ${ }^{1}$ Georgios Kaltsounis ${ }^{2}$ \\ ${ }^{1}$ Department of Haematology, Whittington Hospital, London, UK; ${ }^{2}$ Blood Bank Department, \\ AHEPA University Hospital of Thessaloniki, Greece
}

\begin{abstract}
It has been demonstrated over time that patients with haemoglobinopathies who exhibit a high level of compliance to proper therapy benefit not only from higher life expectancy but also from significantly better quality of life. The treatment of thalassaemia consists of blood transfusions and iron chelation therapy. Managing any complications due to iron overload, performing all necessary clinical and laboratory examinations and dealing effectively with psychological issues are also very important. Blood transfusion scheme must be designed by the treating physician according to the patient's clinical needs. Chelation therapy should be aimed at selecting the right medication and the right dose. Examinations should be as organized as possible, and the management of complications depends significantly on cooperation with experienced specialists in each respective field. Ultimately, effectiveness of treatment and patient's psychological well-being (acceptance of the disease and positive attitude) are the most decisive factors, as they seem to be connected to adherence through a mechanism of positive feedback. Hence, professional psychological support should be part of multidisciplinary care. Difference of point of view between doctor and patient can often be the reason behind misinterpretations or misunderstandings.
\end{abstract}

\section{Introduction}

The treatment of thalassaemia may often seem to a patient like an endless, repetitive procedure that gives the feeling of little, if any, advancement. Due to constant iron overload caused by regular blood transfusions, a steady chelation therapy scheme is important for the patient to maintain relatively steady body iron levels. However, no therapeutic scheme can be effective unless the patient adheres to it properly. The core management of thalassaemia patients is well described as well as the management of complications such as those occurring in the heart, liver or endocrine organs; however there is still relatively poor understanding, or even the perceived need, to tackle the complex psychological issues pertaining to acceptance of the disease and its repercussions, as well as maintenance of a healthy image of oneself.

\footnotetext{
Correspondence: Georgios Kaltsounis, Miaouli 63, 54642, Thessaloniki, Greece.

E-mail: gkaltsoux@yahoo.gr

This work is licensed under a Creative Commons Attribution 4.0 License (by-nc 4.0).

(C) Copyright F. Shah and G. Kaltsounis, 2018

Licensee PAGEPress, Italy

Thalassemia Reports 2018; 8:7484

doi:10.4081/thal.2018.7484
}

\section{Discussion}

The two main aspects of treatment of thalassaemia are transfusion therapy and iron chelation. A proper transfusion scheme must be designed for each patient individually by the treating physician, tailored not only to his clinical needs but also to important aspects of his personal life (including activities related to work, education and family), so as to ensure minimal interference. Blood unit being ready for administration upon patient's arrival is a very effective measure in minimizing patient's distress. Of course, it requires communication and coordination between patient and hospital. Chelation therapy is more challenging. Selecting the optimum regimen (monotherapy with one of the three chelating agents available so far, or a combination of some of them) should take into account clinical status of the patient as well as his preference and his daily activities, and also perhaps availability and cost of medication. Patients should not be discouraged to try different regimens, which may offer them not only adequate chelation but also better quality of life, always under proper supervision. Determining the right dose may often involve a certain level of experimentation and close follow up. Insufficient or excessive doses can lead to iron accumulation and toxicity respectively, which constitute negative experiences for patients and threaten the relationship of trust between patients and doctors.

Patients should feel free to discuss openly about failure to comply without the fear of facing negative attitudes. Management of complications from various organs and/or systems (e.g. cardiac, hepatic, endocrine complications, etc) should be done with close collaboration between the doctors of the thalassaemia unit and experts in each respective field with experience regarding thalassaemic patients. Ideally, a multidisciplinary team should meet and discuss patients, particularly those with complex needs on a regular basis. Moreover, any non-urgent clinical and laboratory examinations needed should be well organized in advanced in order to minimize patients' distress and anxiety, as well as interference with other activities. Ideally, they could be performed on the same days as transfusions as much as possible. Last but not least, psychology plays a major role in compliance. That is a very complex issue, affected by multiple factors (family, society, culture, mentality of each individual patient, etc) that may often need to be addressed through professional help from psychologists, who could be members of the multidisciplinary team. Patients who face problems accepting themselves are often trapped in the stages of grief (Kübler-Ross model), also find it difficult to accept the necessity for proper treatment. It is important to emphasize the impact that the doctor of thalassaemia unit can have over patients. Depending on the approach, a patient may be inspired to pursue better treatment, or feel negativity towards it. Support groups can be formed even spontaneously among patients sharing experiences, knowledge and concerns. Patients with successful adherence to treatment can be viewed as role models by others, whereas patients with low adherence and subsequent aggravating consequences can be viewed as examples to be avoided. 


\section{Conclusions}

The demanding aspects of thalassaemia's treatment as well as the plethora of complex factors that affect a patient's personality and psychological status make proper adherence challenging. A holistic approach by an experienced multidisciplinary team is required, as well as well-organized treatment schemes that will cause minimal interference to patient's lives. A relationship of trust and good communication between patient and doctor is essential in order to avoid misunderstandings due to difference of point of view. Psychological support by other patients or healthcare professionals such as psychologists may be needed for some patients.

\section{References}

1. Trachtenberg FL, Gerstenberger E, Xu Y, et al. Relationship among Chelator Adherence, Change in Chelators, and Quality of Life in Thalassemia. Quality of life research: an international journal of quality of life aspects of treatment, care and rehabilitation. 2014;23(8):2277-2288. doi:10.1007/s11136-014-0671-2.

2. Trachtenberg F, Vichinsky E, Haines D, et al. Iron Chelation Adherence to Deferoxamine and Deferasirox in Thalassemia. American journal of hematology. 2011;86(5):433-436. doi:10.1002/ajh.21993.

3. Trachtenberg FL, Mednick L, Kwiatkowski JL, et al. Beliefs about chelation among thalassemia patients. Health and Quality of Life Outcomes. 2012;10:148. doi:10.1186/14777525-10-148.

4. Aydinok Y, Erermis S, Bukusoglu N, Yilmaz D, and Solak U. (2005), Psychosocial implications of Thalassemia Major. Pediatrics International, 47: 84-89. doi:10.1111/j.1442-200x. 2004.02009.x

5. Coifman KG, Kleinert D, Ross GS, et al. (2012) Negative affect differentiation and adherence during treatment for Thalassemia. International Journal of Behavioral Medicine. Epub ahead of print 21 October 2012. DOI: 10.1007/s12529012-9277-7.

6. Mednick L, Yu S, Trachtenberg F, Xu Y, Kleinert DA, et al.
Symptoms of depression and anxiety in patients with thalassemia: prevalence and correlates in the thalassemia longitudinal cohort. Am J Hematol. 2010;10:802-5.

7. Messina G, Colombo E, Cassinerio E, Ferri F, Curti R, Altamura C, et al. Psychosocial aspects and psychiatric disorders in young adults with thalassemia major. Intern Emerg Med. 2008;3:339-43.

8. Evangeli MM, Mughal K, Porter JB. Which psychosocial factors are related to chelation adherence in thalassemia? A systematic review. Hemoglobin. 2010;34:305-21.

9. Porter JB, Evangeli M, El-Beshlawy A. The challenges of adherence and persistence with iron chelation therapy. Int $\mathrm{J}$ Hematol. 2011;94:453-60.

10. Fortin PM, Madgwick KV, Trivella M, Hopewell S, Doree C, Estcourt LJ. Interventions for improving adherence to iron chelation therapy in people with sickle cell disease or thalassaemia. The Cochrane database of systematic reviews. 2016;2016(9):CD012349. doi:10.1002/14651858.CD012349.

11. Al-Kloub MI, A Bed MA, Al Khawaldeh OA, et al. Predictors of non-adherence to follow-up visits and deferasirox chelation therapy among Jordanian adolescents with Thalassemia major. Pediatr Hematol Oncol. 2014;31(7):624-637.

12. Bazi A, Sargazi-Aval O, Safa A, Miri-Moghaddam E. Healthrelated Quality of Life and Associated Factors Among Thalassemia Major Patients, Southeast of Iran. J Pediatr Hematol Oncol. 2017 Aug 30. doi: 10.1097/MPH. 0000000000000963. [Epub ahead of print]

13. Anie KA, Massaglia P. Psychological therapies for thalassaemia. Cochrane Database of Systematic Reviews 2014, Issue 3. Art. No.: CD002890. DOI: 10.1002/14651858.CD002890. pub2.

14. Tsiantis J, Xypolita-Tsantili D, Papadakou-Lagoyianni S. Family reactions and their management in a parents group with beta-thalassaemia. Archives of Disease in Childhood. 1982;57(11):860-863.

15. Mischak H, Ioannidis JP, Argiles A, et al. Implementation of proteomic biomarkers: making it work. European Journal of Clinical Investigation. 2012;42(9):1027-1036. doi:10.1111/j. 1365-2362.2012.02674.x. 